\title{
Research on the adaptability of vehicles with different technical types to the China 6 regulation standard
}

\author{
Feng Yan*, Jian Ling, Chunbei Dai, Yuewei Wang, and Jingyuan Li \\ China Automotive Technology \& Research Center CO., Ltd., Tianjin 300300, China
}

\begin{abstract}
Keywords: vehicles with different technical types, China 6 regulation, emission behaviour.
\end{abstract}

\begin{abstract}
A test fleet including 47 gasoline vehicles with 6 different technical types was organized, and the adaptability of these vehicles under China 6 standard was studied. By analyzing the performance of the vehicles tested in laboratory and in real-world, technical types that could simultaneously reconcile emission and fuel consumption performance were proposed. The results show that all vehicles were well performed under laboratory conditions, but in real-world conditions, 50\% direct injection vehicles without GPF would fail the RDE test. On the other hand, vehicles with GPF had better performance, all of which passed the RDE tests even if the conformity factor decreased from 2.1 to 1 . In addition, it is found that the fuel consumption of the DI vehicles were lower than that of the PFI vehicles. As the DI vehicles with GPF showed better performance on the balance of emission and fuel consumption, indicating that they may have better potentials to deal with the increasing tightened emission and fuel consumption standards at the same time.
\end{abstract}

\section{Introduction}

At the end of 2016, the Ministry of Ecology and Environment of the People's Republic of China and the General Administration of Quality Supervision, Inspection and Quarantine of the People's Republic of China jointly issued the "Limits and measurement methods for emissions from light-duty vehicles (CHINA 6)", which can be abbreviated to CN6 [1]. Comparing to CN5 [2], major changes in CN6 were concentrated in four aspects: 1) by referring to European experiences, CN6 introduced the Worldwide harmonized Light vehicles Test Procedure (WLTP) [3], and the test cycle was changed from the New European Driving Cycle (NEDC) to Worldwide harmonized Light-duty vehicles Test Cycle (WLTC) accordingly, 2) by referring to European experiences, real-driving emission (RDE) tests was introduced to control the real-world vehicle emissions [4], 3) by referring to the American standards, the evaporative emission test was modified from 1 day diurnal to 2 day diurnal, and Onboard Refueling Vapor Recovery (ORVR) requirements [5] were introduced, 4) tightened the requirements of on-board diagnostic system by referring to US

\footnotetext{
*Corresponding author: yanfeng2015@catarc.ac.cn
} 
OBD II [6]. Comparing to CN5, the emission limits of CN6 are more severe, which treats no difference between SI and CI vehicles as 'fuel neutrality' concept was introduced, the NOx emission of CI and PN emission of SI are now facing the same challenge from the new regulation other than very loose limits or even no limits in CN5. The emission limits of CN6 will be implemented in two phases, CN6a and CN6b, where the limits of CN6a are roughly equal to Euro6c, and the emission limits of $\mathrm{CN} 6 \mathrm{~b}$ are further tightened, some limits like NOx, NMHC, THC and etc, are more than 40\% lower comparing to CN6a. Meanwhile, the Chinese government has announced plans to roll out a three-year project to ensure greater achievements in air pollution control in major areas like the Beijing-Tianjin-Hebei and surrounding areas, the Yangtze River Delta, the Fenhe and Weihe plain and so on. Some of these major areas have already announced to pull ahead the implementation schedule of CN6b to 2019, which is a serious challenge leaving very short time for the OEMs to upgrade and verify their products. Thus, most of the OEMs are working on the CN6b prototype directly, but even so, the situation for the whole industry is very urgent.

In this research, a test fleet contained nearly 50 vehicles with different technical types was organized, and the adaptability of these vehicles to the CN6b regulation was studied. By analyzing the emission and fuel consumption performance in laboratory and on real road, technical types that have more potentials to deal with the increasing tightened emission and fuel consumption standards at the same time was recommended.

\section{Basic information}

For nearly $90 \%$ of light-duty vehicles (LDV) in China are gasoline ones, so for a better representative, a test fleet contained 47 gasoline vehicles with different technical types was organized. Technical types can be classified by direct injection (DI) or port fuel injection (PFI), natural aspirated or charged, with or without gasoline particle filter (GPF), forms 6 combinations - PFI vehicles, PFI charged vehicles, PFI charged GPF vehicles, DI vehicles, DI charged vehicles and DI charged GPF vehicles, each has a proportion of about $39 \%, 2 \%$, $2 \%, 13 \%, 35 \%$ and $9 \%$ respectively as shown in Figure 1, additionally, all of the vehicles were new ones with mileages around $3000 \mathrm{~km}$.

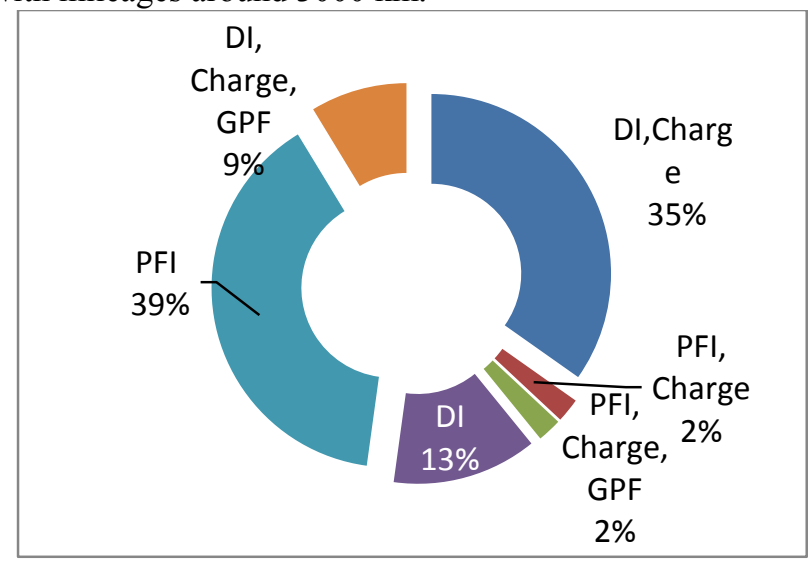

Fig. 1. Composition of test fleet.

\section{Result and discussions}

Figure 2 shows the PN and NOx emission of the test fleet during RDE tests. For the RDE emissions are only measured and recorded in CN6a, so the limits in the following 
discussion are all CN6b limits. The CN6 type I limits are listed in Table 1. For RDE, the emissions should not be higher than the pollutant-specific not-to-exceed (NTE) values defined as:

$$
\mathrm{NTE}_{\text {pollutant }}=\mathrm{CF}_{\text {pollutant }} \times \mathrm{CN} 6 \text { (type I limit) }
$$

Where $\mathrm{CF}_{\text {pollutant }}$ is the conformity factor. For now, the conformity factor of CN6 for both NOx and PN are 2.1, which will be evaluated by July 2022.

Table 1. The CN6 type I limits.

\begin{tabular}{cccccccc}
\hline & $\begin{array}{c}\mathrm{CO} \\
(\mathrm{mg} / \mathrm{km})\end{array}$ & $\begin{array}{c}\mathrm{THC} \\
(\mathrm{mg} / \mathrm{km})\end{array}$ & $\begin{array}{c}\mathrm{NMHC} \\
(\mathrm{mg} / \mathrm{km})\end{array}$ & $\begin{array}{c}\mathrm{NOx} \\
(\mathrm{mg} / \mathrm{km})\end{array}$ & $\begin{array}{c}\mathrm{N} 2 \mathrm{O} \\
(\mathrm{mg} / \mathrm{km})\end{array}$ & $\begin{array}{c}\mathrm{PM} \\
(\mathrm{mg} / \mathrm{km})\end{array}$ & $\begin{array}{c}\mathrm{PN} \\
(\# / \mathrm{km})\end{array}$ \\
\hline $\mathrm{CN} 6 \mathrm{a}$ & 700 & 100 & 68 & 60 & 20 & 4.5 & $6.0 \times 10^{11}$ \\
$\mathrm{CN} 6 \mathrm{~b}$ & 500 & 50 & 35 & 35 & 20 & 3.0 & $6.0 \times 10^{11}$ \\
\hline
\end{tabular}

In fact, the conformity factor should be expressed as $1+$ margin, which is a parameter taking into account the additional measurement uncertainties introduced by the PEMS equipment. In Europe, the NOx CF was initially 2.1, and will be revised to 1.43 in package 4, and the PN CF was set to 1.5 in package 3. All the CFs are subject to an annual review and shall be revised as a result of the improved quality of the PEMS procedure or technical progress. From the experience of Europe and for the RDE situations are not as severe for gasoline vehicles as for diesel vehicles, the CFs in CN6 are probably reduce, thus, in Figure 2 , lines with different colors are used to mark the RDE limits for different CFs, red is 2.1, blue is 1.5 , and black is 1.0 .

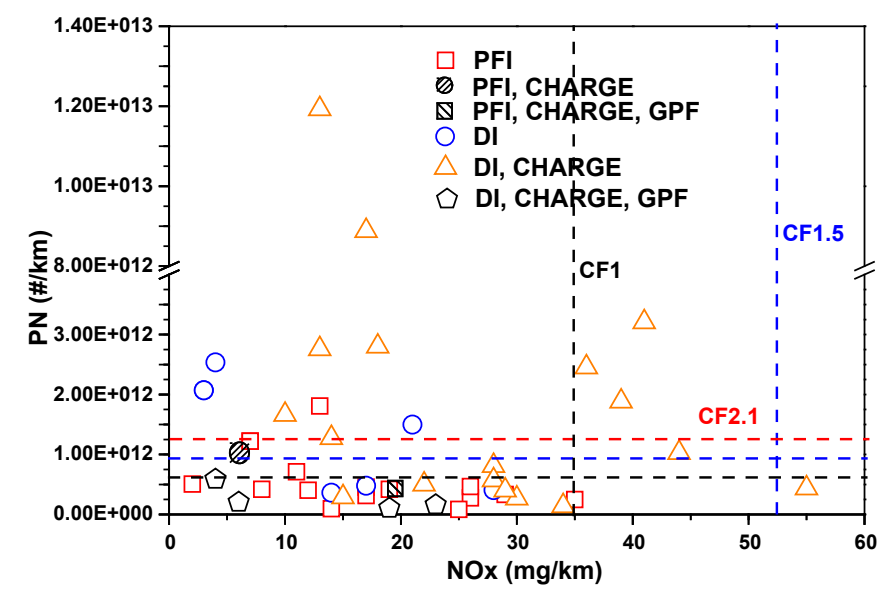

Fig. 2. The PN and NOx emission of the test fleet during RDE tests.

It is revealed in Figure 2 that the NOx emissions were well performed during RDE tests, all of which were below the CN6 NTE limit under the current proposed CF 2.1, but the PN emissions, on the other hand, exceeded the NTE limits in various degrees depending on the technical types of the vehicle - 6\% PFI vehicles and 50\% DI vehicles without GPF failed the RDE tests for exorbitant PN emissions. The fuel-air mixing process is relatively shorter for the DI engine than the PFI engine, which is easier to form local fuel rich areas leading to high particulate emissions [7-8]. The GPF seems to be a good choice for the reduction of PN emission which has been reported by many researches under engine test bench studies 
in laboratory conditions [9-12]. Our study revealed that even in real-world conditions vehicles with GPF still performed well, no matter PFI or DI, natural aspirated or charged, all passed the RDE tests. When CF is reduced to 1.5 , more vehicles - nearly $60 \% \mathrm{DI}$ vehicles without GPF and nearly $18 \%$ PFI vehicles failed the RDE tests, meanwhile, vehicles with GPF still performed well at this time. If CF is further reduced to 1.0 , about $63 \%$ DI vehicles without GPF and nearly 30\% PFI vehicles failed the RDE tests, still all vehicles with GPF emitted less pollutant than the NTE limits with a CF of 1.0. For a better illustration, the failure rates of different technical types are also attached in Table 2.

Table 2. Failure rates for different technical types.

\begin{tabular}{cccccccc}
\hline CFs & PFI & $\begin{array}{c}\text { PFI } \\
\text { charged }\end{array}$ & $\begin{array}{c}\text { PFI } \\
\text { charged } \\
\text { GPF }\end{array}$ & DI & $\begin{array}{c}\text { DI } \\
\text { charged }\end{array}$ & $\begin{array}{c}\text { DI charged } \\
\text { GPF }\end{array}$ & Total \\
\hline 2.1 & $6 \%$ & $0 \%$ & $0 \%$ & $50 \%$ & $50 \%$ & $0 \%$ & $28 \%$ \\
1.5 & $12.5 \%$ & $100 \%$ & $0 \%$ & $50 \%$ & $61 \%$ & $0 \%$ & $37 \%$ \\
1 & $25 \%$ & $100 \%$ & $0 \%$ & $50 \%$ & $66.7 \%$ & $0 \%$ & $43 \%$ \\
\hline
\end{tabular}

Figure 2 had shown the emissions of new vehicles, which were more like the emission status in type approvals, but in actual usage the after treatment systems will inevitably aging which will affect the conversion/capture efficiency of pollutants, resulting in the increase of emissions which were regulated in legislation as deterioration factors (DFs). In fact, the DFs have considered the worst emission situations caused by after treatment systems aging - when vehicles meet the full useful life mileage. According to CN6 the DFs can be obtained by dividing emissions at $160,000 \mathrm{~km}$ (CN6a) or $200,000 \mathrm{~km}$ (CN6b) by emissions at $6400 \mathrm{~km}$ for each pollutant. For the completion of the vehicle durability test for the whole fleet is not feasible, thus in this study the assigned DFs the CN6 regulation recommended were used to simulate the deterioration of vehicle emissions at full useful life mileage. The assigned DFs in CN6 regulation are listed in Table 3.

Table 3. The assigned DFs in CN6 regulation.

\begin{tabular}{cccccccc}
\hline \multirow{2}{*}{ Engine type } & \multicolumn{7}{c}{ DF } \\
\cline { 2 - 8 } & $\mathrm{CO}$ & THC & NMHC & NOX & N2O & PM & PN \\
\hline SI & 1.8 & 1.5 & 1.5 & 1.8 & 1.0 & 1.0 & 1.0 \\
CI & 1.5 & 1.0 & 1.0 & 1.5 & 1.0 & 1.0 & 1.0 \\
\hline
\end{tabular}

In CN6, the extensions for tailpipe emission test and RDE test are the same, which required the same essential parts that directly related to emissions like engine parameters, pollutant control devices, test mass, transmission ratio and so on. Thus, in this study, the assigned DFs of tailpipe emission were used in RDE tests, and the PN and NOx emissions after severe deteriorations were finally obtained as shown in Figure 3.

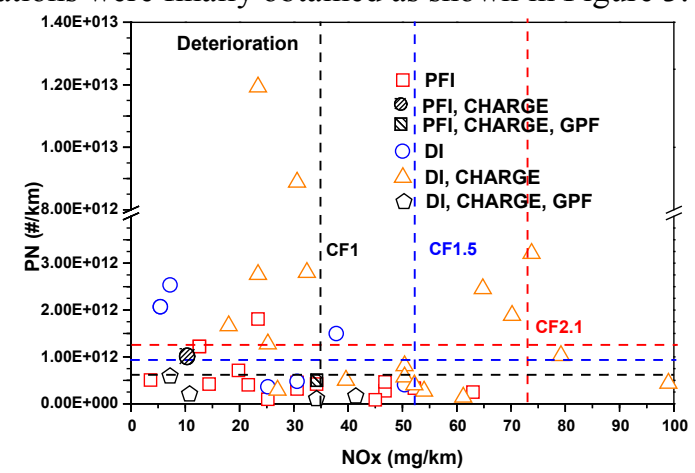


Fig. 3. The PN and NOx emission of the test fleet after severe deteriorations during RDE tests.

It is revealed in Figure 3 that if emission deteriorations were considered, the failure rate of RDE for different technical types raised in varying degrees. Nearly $58 \%$ DI vehicles without GPF failed the RDE tests when CF is 2.1 , nearly $71 \%$ DI vehicles without GPF and $24 \%$ PFI vehicles failed the RDE tests when CF is 1.5 , and nearly $87.5 \%$ DI vehicles without GPF and 47\% PFI vehicles failed the RDE tests when CF is 1.0, still all of the DI vehicles with GPF performed well at this time with nearly $0 \%$ failure rate under any of those CFs. It is revealed that GPF can effectively control PN emissions during RDE, which can be regarded as an insurance to restrain PN under the proposed NTE limit to a large extent for the DI vehicles. To further understand the roles of GPF in real-driving conditions, two times of RDE tests were conducted on the same DI charged vehicle in the fleet, once with GPF, once removed GPF. Figure 4 shows the PN emission of these two tests at different engine speed and load. To insure the consistency of the test status, the same driver and route was selected, and the vehicle was preconditioned for 30 minutes in chassis dynamometer under WLTC cycle, soaked in $23 \pm 3 \mathrm{degC}$ environment for about 8 hours before each test. It is revealed in Figure 4 that the PN emissions increased significantly in the engine speed - load MAP when GPF was removed, approximately two orders of magnitude at low load and low engine speed conditions, and one order of magnitude at high load and high engine speed conditions.

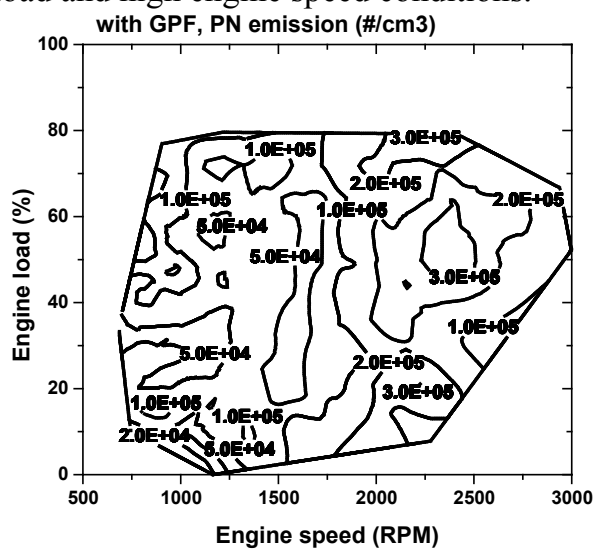

(a) With GPF

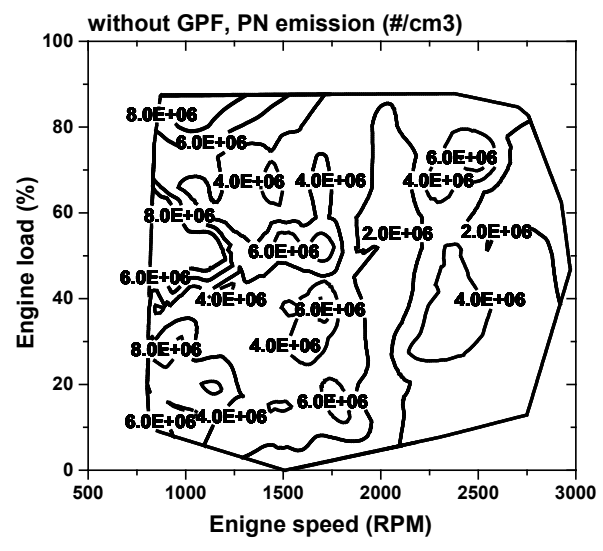

(b) Without GPF

Fig. 4. PN emissions for the same DI vehicle at different engine speed and engine load, once with GPF (a), once without GPF (b).

Figure 5 shows the PN and NOx emissions of the test fleet during WLTC cycle in new vehicle state (a), and in aging state (b) by taking the deterioration factors into account. It is revealed in Figure 5 that the emissions under test cycles were much lower than that in real-world conditions, the NOx and PN emissions were still below the regulation limits of $\mathrm{CN} 6 \mathrm{~b}$ even if deteriorations were considered. 


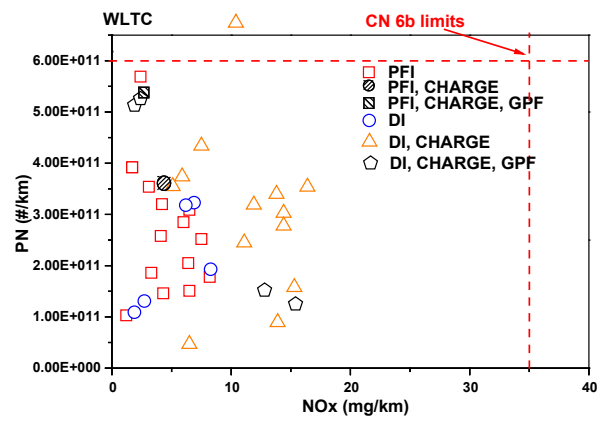

(a) New vehicle state

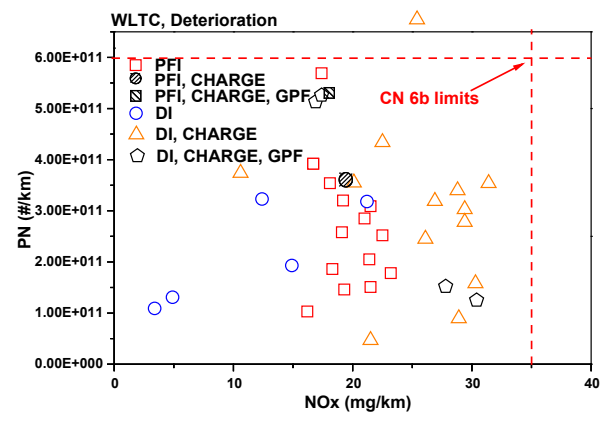

(b) Aging state

Fig. 5. PN and NOx emissions of the test fleet during WLTC cycle in (a) new vehicle state, and in (b) aging state by taking the deterioration factors into account.

Figure 6 shows the ratio of emission in RDE and in lab conditions of the test fleet, which revealed that $72.3 \%$ vehicles emitted more NOx and more PN simultaneously in real-world than in laboratory, $21.3 \%$ vehicles emitted more NOx but less PN in real-world than in laboratory, $4.2 \%$ vehicles emitted less NOx but more PN in real-world than in laboratory, only 1 sample emitted less NOx and less PN in real-world than in laboratory. The emission difference between RDE and test cycle can be as much as 8 and 12 times for $\mathrm{PN}$ and NOx respectively, which were huge enough to influence the energy saving and emission reduction effect in real-world as new regulation is introduced.

The fuel consumption of the test fleet were listed in Figure 7 (a), all met the current proposed regulation limit. To better understand the correlation between technical types and fuel consumptions, a normalized parameter representing the fuel consumption at unit mass driven by unit power was introduced, which can be calculated as:

$$
\mathrm{FC}_{\mathrm{n}}=\frac{\mathrm{FC}}{\mathrm{CM} \times \mathrm{P}}
$$

where FC represents the fuel consumption, CM represents the curb mass of the vehicle, while $\mathrm{P}$ represents the average engine power during the whole test, which can be calculated as:

$$
\mathrm{p}=\frac{\int_{0}^{\mathrm{t}} \mathrm{a} \times \mathrm{v} \times \mathrm{CM}+\mathrm{A} \times \mathrm{v}+\mathrm{B} \times \mathrm{v}^{2}+\mathrm{C} \times \mathrm{v}^{3}}{\mathrm{t}}
$$

where a represents the acceleration, $v$ represents the vehicle speed, $A, B, C$ represent the road load coefficients, $t$ represents the test duration.

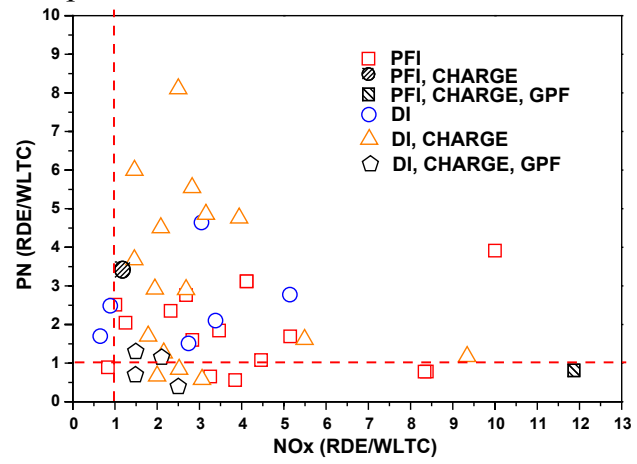

Fig. 6. The ratio of emissions in RDE and in lab conditions of the test fleet. 


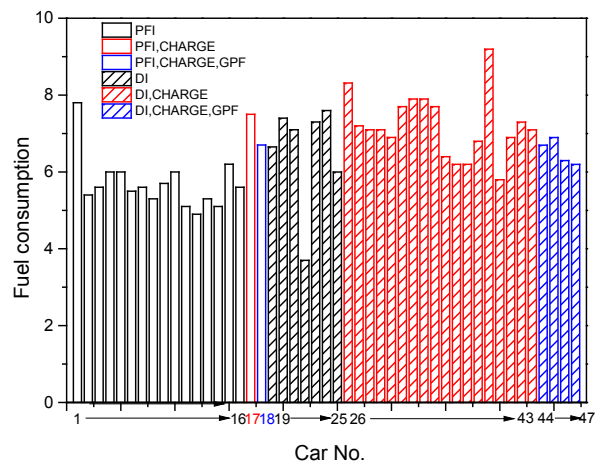

(a) Fuel consumption according to regulation

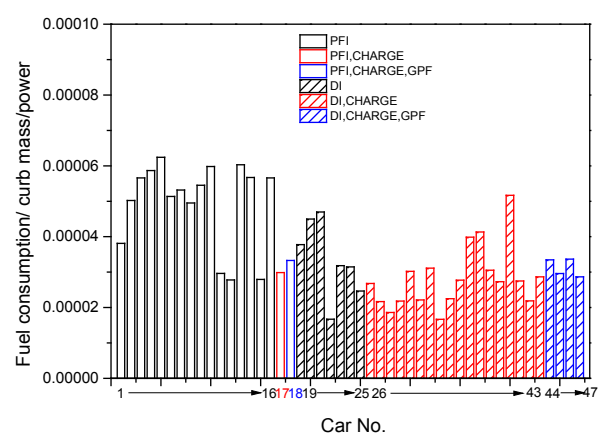

(b) Fuel consumption at unit mass driven by unit power

Fig. 7. the fuel consumptions of the test fleet, (a) according to regulation,(b) at unit mass driven by unit power.

It is revealed in Figure 7 (b) that the fuel consumptions at unit mass driven by unit power of DI vehicles were normally lower than that of PFI vehicles. The fuel consumption target is tightening all over the world, the situation in China is that a target of $5.0 \mathrm{~L} / 100 \mathrm{~km}$ has to be met in 2020 , which is $36 \%$ lower than the $6.9 \mathrm{~L} / 100 \mathrm{~km}$ target in 2015 , thus, the manufacturers put more enthusiasm on DI prototypes to deal with the increasingly tightened target. According to Figure 2 and Figure 7, it can be speculated that under the high pressure of emission requirements especially RDE and fuel consumption target, technical types of DI vehicle with GPF shows better performance on the balance of emission and fuel consumption, which has more potentials to deal with the increasing tightened emission and fuel consumption standards at the same time.

\section{Conclusions}

In this study, a test fleet including 47 gasoline vehicles with 6 different technical types was organized, and the adaptability of these vehicles under China 6 standard was studied. By analyzing the performance of the vehicles tested in laboratory and in real-world, technical types that could simultaneously reconcile emission and fuel consumption performance were proposed. The following conclusions are obtained:

1) In laboratory conditions, all vehicles were well performed even if the deterioration factors were considered, but in real-world conditions, $72.3 \%$ vehicles emitted more NOx and more PN simultaneously than in laboratory conditions.

2) The NOx emissions were well performed during RDE tests, but the PN emissions exceeded the proposed NTE limits in various degrees depending on the technical types of the vehicle. More than 50\% DI vehicles without GPF failed the RDE test, but all vehicles with GPF passed the RDE tests even if the conformity factor decreased from 2.1 to 1 .

3) DI vehicles with GPF showed better performance on the balance of emission and fuel consumption, which may have more potential to deal with the increasing tightened emission and fuel consumption standards at the same time.

Financial support was provided by the special item of atmosphere of the National key research and development plan through its key project funding 2017YFC0211004 and 2017YFC0211005.

\section{Abbreviations}




$\begin{array}{lll}\text { RDE } & - & \text { Real driving emissions } \\ \text { WLTP } & - & \text { Worldwide harmonized Light vehicles Test Procedure } \\ \text { WLTC } & - & \text { Worldwide harmonized Light-duty vehicles Test Cycle } \\ \text { NEDC } & - & \text { New European Driving Cycle } \\ \text { ORVR } & - & \text { Onboard Refueling Vapor Recovery } \\ \text { NTE } & - & \text { Not-To-Exceed } \\ \text { GPF } & - & \text { Gasoline Particulate Filter } \\ \text { DF } & - & \text { deterioration factor } \\ \text { CF } & - & \text { Conformity factor } \\ \text { ISC } & - & \text { In-Service Conformity } \\ \text { PFI } & - & \text { Port fuel injection } \\ \text { DI } & - & \text { Direct injection } \\ \text { PEMS } & - & \text { Portable Emissions Measurement Systems } \\ \text { LDV } & - & \text { Light-duty vehicle }\end{array}$

\section{References}

1. Limits and measurement methods for emissions from light-duty vehicles (CHINA 6) (2016).http://kjs.mep.gov.cn/jbhbz/bzwb/dqhjbh/dqydywrwpfbz/201612/W020171207 355626647621.pdf

2. Limits and measurement methods for emissions from light-duty vehicles (CHINA 5) (2013).http://kjs.mep.gov.cn/hjbhbz/bzwb/dqhjbh/dqydywrwpfbz/201309/W02013110 5534056881723.pdf

3. Ciuffo, B. et al., (2015). The development of the World-Wide Harmonized Test Procedure for Light Duty Vehicles (WLTP) and the Pathway for its Implementation into the EU Legislation. Transportation Research Board Meeting , 2015 , 68 (4) :302-8

4. COMMISSION REGULATION (EU) 2017/1151 (2017). https://eur-lex.europa.eu/legal-content/EN/TXT/?qid=1535438727587\&uri=CELEX:3 2017R1151

5. Air Quality: Widespread Use for Onboard Refueling Vapor Recovery and Stage II Waiver (2015). www.federalregister.gov. Retrieved 2015-10-27.

6. OBD II enforcement regulation, section 1968.5 of title 13, California Code of Regulations (2016). https://www.arb.ca.gov/regact/obd02/obd02.htm

7. Miao, S., et al., (2017). Development of a Gasoline Particulate Filter for China 6(b) Emission Standards. SAE paper 2017-24-0135.

8. Reggie, Zhan, et al,. (2010). Simultaneous reduction of PM, HC, CO and NOx emissions from a GDI engine. SAE paper 2010-01-0365.

9. Bonandrini, G., et al,. (2012). Numerical study on multiple injection strategies in DISI engines for particulate emission control. SAE paper 2012-01-0400.

10. Tak W. Chan, et al,. (2012). Evaluation of a gasoline particulate filter to reduce particle emissions form a gasoline direct injection vehicle. SAE paper 2012-02-1727.

11. Ito, Y., et al., (2013). Advanced Ceramic Wall Flow Filter for Reduction of Particulate Number Emission of Direct Injection Gasoline Engines. SAE paper 2013-01-0836.

12. Spicher, U., et al,. (1999). Gasoline direct injection (GDI) engines development potentialities. SAE paper 1999-01-2938. 